\title{
Changes in magnetic resonance imaging disease measures over 3 years in mildly disabled patients with relapsing-remitting multiple sclerosis receiving interferon $\beta$-1a in the COGnitive Impairment in MUltiple Sclerosis (COGIMUS) study
}

\author{
Stefano Bastianello ${ }^{1 *}$, Elisabetta Giugni ${ }^{2}$, Maria Pia Amato ${ }^{3}$, Maria-Rosalia Tola ${ }^{4}$, Maria Trojano ${ }^{5}$, Stefano Galletti ${ }^{6}$,
} Giacomo Luccichenti ${ }^{7}$, Mario Quarantelli ${ }^{8}$, Orietta Picconi ${ }^{9}$ and Francesco Patti ${ }^{10}$, for the COGIMUS study group

\begin{abstract}
Background: Conventional magnetic resonance imaging (MRI) has improved the diagnosis and monitoring of multiple sclerosis (MS). In clinical trials, MRI has been found to detect treatment effects with greater sensitivity than clinical measures; however, clinical and MRI outcomes tend to correlate poorly.

Methods: In this observational study, patients ( $n=550$; $18-50$ years; relapsing-remitting MS [Expanded Disability Status Scale score $\leq 4.0]$ ) receiving interferon (IFN) $\beta$-1a therapy (44 or $22 \mu \mathrm{g}$ subcutaneously [sc] three times weekly [tiw]) underwent standardized MRI, neuropsychological and quality-of-life (QoL) assessments over 3 years. In this post hoc analysis, MRI outcomes and correlations between MRI parameters and clinical and functional outcomes were analysed.

Results: MRI data over 3 years were available for 164 patients. T2 lesion and T1 gadolinium-enhancing (Gd+) lesion volumes, but not black hole $(\mathrm{BH})$ volumes, decreased significantly from baseline to Year $3(P<0.0001)$. Percentage decreases (baseline to Year 3) were greater with the $44 \mu \mathrm{g}$ dose than with the $22 \mu \mathrm{g}$ dose for T2 lesion volume $(-10.2 \%$ vs $-4.5 \%, P=0.025)$ and $\mathrm{T} 1 \mathrm{BH}$ volumes $(-7.8 \%$ vs $+10.3 \%, P=0.002)$. A decrease in $\mathrm{T} 2$ lesion volume over 3 years predicted stable QoL over the same time period. Treatment with IFN $\beta-1 \mathrm{a}, 44 \mu \mathrm{g}$ sc tiw, predicted an absence of cognitive impairment at Year 3.
\end{abstract}

Conclusion: Subcutaneous IFN $\beta$-1a significantly decreased MRI measures of disease, with a significant benefit shown for the $44 \mu \mathrm{g}$ over the $22 \mu \mathrm{g}$ dose; higher-dose treatment also predicted better cognitive outcomes over 3 years.

\section{Background}

Magnetic resonance imaging (MRI) can provide valuable information on the type, extent and location of pathological lesions in patients with multiple sclerosis (MS). Increasingly, MRI is routinely used in the diagnosis and monitoring of MS, being integral to the McDonald criteria [1]. In addition, MRI measures have been widely used as secondary [2-5] and, more recently, primary [6] outcome

\footnotetext{
* Correspondence: stefano.bastianello@yahoo.it

'National Neurological Institute, C Mondino Foundation, IRCCS, Via Ferrata, I27100, Pavia, Italy

Full list of author information is available at the end of the article
}

measures in large clinical trials of new MS therapies. In the pivotal PRISMS (Prevention of Relapses and disability by Interferon- $\beta$-1a Subcutaneously in Multiple Sclerosis) study, subcutaneous (sc) interferon (IFN) $\beta-1 \mathrm{a}, 44$ or 22 $\mu \mathrm{g}$ three times weekly (tiw), significantly reduced relapserelated outcomes in patients with relapsing-remitting MS (RRMS) [7]. Treatment with sc IFN $\beta-1$ a was also found to significantly reduce MRI measures of disease at 2 years compared with placebo [7]. Significant effects included reductions in T2 burden of disease (BOD; $P<0.0001$ for both doses vs placebo), the number of $\mathrm{T} 2$ active lesions $(P<0.0001$ for both doses vs placebo), and the number of 
combined unique active (CUA) lesions $(P<0.0001$ for both doses vs placebo) [4,7]. Furthermore, a significant benefit of the higher over the lower dose was seen for some measures, including the number of active T2 lesions, as reported for clinical outcomes [7]. Beneficial effects of treatment with sc IFN $\beta-1 \mathrm{a}$ on MRI measures of disease were also detected in this patient cohort after 7 to 8 years of follow-up, again with evidence of a dose effect [8].

In addition to long-term monitoring of treatmentrelated outcomes, MRI, unlike clinical measures, can detect early treatment effects. Recently, rapid benefits of IFN $\beta-1 \mathrm{a}$ in RRMS were detected using MRI. Notably, patients receiving active treatment had $69 \%$ fewer CUA lesions than those receiving placebo after 16 weeks of treatment $(P<0.001)[6]$. A post hoc analysis revealed a significant effect on the number of CUA lesions as early as week 4 after starting treatment [6]. The effect of IFN $\beta-1 \mathrm{a}$ on 'newer' MRI measures including T1 black holes $(\mathrm{BH})$, which indicate areas of axonal loss and permanent tissue damage, is less clear.

Although MRI provides valuable insights into MS, conventional MRI measures have tended to correlate poorly with clinical outcomes $[9,10]$. This discrepancy is believed to arise for several reasons, such as the presence of clinically silent MRI lesions, functional plasticity, and the failure of neurological measures such as the Expanded Disability Status Scale (EDSS) to capture psychosocial symptoms and cognitive impairment.

Cognitive impairment is experienced by up to $65 \%$ of patients with MS [11] and can result in considerable disability, loss of social functioning, and reduced quality of life (QoL) [12,13]. Previous studies in MS have reported associations between the development of brain MRI lesions and cognitive impairment $[14,15]$. In the prospective, multicentre, observational COGIMUS (COGnitive Impairment in MUltiple Sclerosis) study of mildly disabled patients with RRMS, we reported that $\mathrm{T} 2$ hyperintense and T1 hypointense lesion volumes at baseline were significantly higher in patients with cognitive impairment than in those without [16]. Indeed, T2 lesion volume was also found to be a significant predictor of cognitive impairment at baseline [16]. In addition, weak associations were found between cognitive performance test results and specific MRI measures in this population [16].

In COGIMUS, $\sim 20 \%$ of patients who received sc IFN $\beta-1$ a were found to have cognitive impairment at baseline $(22 \mu \mathrm{g}$ sc tiw: $24.2 \%, 44 \mu \mathrm{g}$ sc tiw: $18.6 \%[P=$ $0.145])$ despite having only a low level of physical disability (mean [standard deviation; SD] EDSS score was 1.8 [1.0]) [16,17]. Further, 3-year results from COGIMUS suggested that treatment with IFN $\beta-1 \mathrm{a}, 44$ or 22 $\mu \mathrm{g}$ sc tiw, may have a dose-dependent protective effect on cognition in this mildly disabled patient population $[17,18]$. Here we report the results of a post hoc analysis of the longitudinal effects of treatment on MRI measures of disease over 3 years in the COGIMUS study. Associations between MRI measures and cognitive and patient-reported outcomes were assessed to explore whether beneficial treatment effects on MS lesions were related to those on cognition.

\section{Methods}

\section{Patients and study design}

COGIMUS was a prospective, multicentre, observational, 3 -year study to assess the effects of IFN- $\beta$ treatment on cognition in a large cohort of Italian patients with RRMS. The study was performed with respect to the Declaration of Helsinki and according to good clinical practice recommendations (Ethics Committee registration number 78 of the Clinical Experiments Register; 2002, DOI78 Prot. 43 02/08/2002). Full details of the study design have been described elsewhere $[16,17]$. Briefly, patients aged 18-50 years, with a diagnosis of RRMS (McDonald criteria) [1] and an EDSS score of $\leq 4.0$, and who were naïve to disease-modifying drugs (DMDs), were eligible for inclusion in the study. Patients were assigned to one of three IFN- $\beta$ treatment regimens: sc IFN $\beta$-1a (44 or 22 $\mu \mathrm{g}$ tiw), intramuscular (im) IFN $\beta-1 \mathrm{a}$ (30 $\mu$ g once weekly), or sc IFN $\beta$-1b ( $250 \mu \mathrm{g}$ every other day); the choice of treatment was made entirely at the discretion of the treating physician following discussion with the individual patient. All patients gave written informed consent. Most patients enrolled into the study (459/550; 83.5\%) were assigned sc IFN $\beta$-1a treatment. As reported elsewhere [17], 64 patients (11.6\%) were assigned im IFN $\beta$ $1 \mathrm{a}$ and 27 patients $(4.9 \%)$ were assigned sc IFN $\beta-1 \mathrm{~b}$, of whom only 13 and 19 patients, respectively, were available for follow-up at 3 years; due to the low patient numbers and high drop-out rates, the current analyses were restricted to the cohort of patients who received sc IFN $\beta-1$ a. MRI outcomes were compared in patients who received sc IFN $\beta-1 \mathrm{a}, 44$ or $22 \mu \mathrm{g}$ sc tiw; additional post hoc analyses were performed on pooled data from these two patient groups.

\section{MRI assessments}

Standardized MRI scans were performed using a 1.5 Tesla scanner to determine $\mathrm{T} 1$ gadolinium-enhancing $(\mathrm{Gd}+)$ lesions, and $\mathrm{T} 1$ hypointense and $\mathrm{T} 2$ hyperintense lesion volumes. Brain MRI scans were performed annually with strict repositioning criteria using standard landmarks. All centres followed a standardized MRI protocol [16]. Briefly, MRI scans were obtained on a high-field magnet. Fortyeight interleaved 3-mm slices were acquired for each sequence, on axial plane; a 250 field of view (FOV) and $256 \times 256$ matrix were obtained. Specifications included pre-contrast T1: TR 500-650, TE 10-20, one excitation, 6-minute acquisition; post-contrast T1: TR 500-650, TE 
10-20, one excitation, 6-minute acquisition; dual-echo sequence: TR 2000-3200, TE 20-50 and TE 80-120, two excitations, turbo factor 4-6, 5-minute acquisition; T2 Fast-FLAIR: TR 6000-9999, TE 150-200, TI 2000-2500, one excitation, turbo factor 11-18, 6-8 minutes acquisition. Scans were analysed centrally by expert observers who were blinded to clinical data.

\section{Neuropsychological, QoL and psychosocial assessments}

Cognitive performance was assessed at baseline and annually up to Year 3. The results of neuropsychological assessments have been reported in detail elsewhere [16]. Briefly, cognitive performance was assessed using Rao's Brief Repeatable Battery and the Stroop Test. Impaired performance was defined as a test result $1 \mathrm{SD}$ below Italian mean normative values [19]; impaired performance on $\geq 3$ tests indicated cognitive impairment [16]. As the number of patients with impaired performance on $\geq 3$ tests and full MRI data was too low for statistical analysis, for the purposes of this post hoc study we performed additional analyses to assess the association between outcomes and cognition in which cognitive impairment was defined as impaired performance on $\geq 2$ tests.

Intelligence quotient (IQ) was determined using the Brief Intelligence Test [20]. Fatigue (Fatigue Impact Scale; FIS) [21], depressive symptoms (Hamilton Depression Rating Scale; HDRS [22], social functioning (Environmental Status Scale; ESS) [23] and QoL (Multiple Sclerosis Quality of Life-54 [MSQoL-54] questionnaire) were assessed at baseline and annually thereafter.

\section{Statistical analyses}

Quantitative variables were expressed as means (SD) and medians (Q1, Q3). Discrete and continuous variables were analysed using non-parametric tests: the Mann-Whitney test for between-group comparisons, the Wilcoxon signed rank test for repeated comparisons, and Pearson's chi-square test or Fisher's exact test to compare categorized proportions of patients.

Multivariate logistic regression was used to test associations between MRI variables and clinical and QoL outcomes. Only variables that were significant $(P \leq 0.05)$ in univariate models were included in the multivariate model. A clinically relevant change in QoL score was defined as a change of 0.5 - SD or more from baseline to Year $3(0.5+$ SD for the ESS and its subscales) [24]. No adjustments were made for multiple comparisons and there was no imputation of missing data. All statistical analyses were performed using SAS 8.2 and STATA 8.2.

\section{Results}

\section{Patients and data availability}

Baseline MRI data were available for 327/459 (71.2\%) patients receiving sc IFN $\beta-1 a$, for whom MRI data over
3 years of follow-up were available for 164 (35.7\%), although all parameters were not available at every time point for all patients. Data were missing for 163 patients either because these patients were lost to follow-up or because the scans were unreadable for technical reasons (e.g. software upgrade, optical disc damage).

Among the 164 patients who had 3-year follow-up MRI data, mean (SD) age was 33 (8) years and $102(62.2 \%)$ were women; mean (SD) disease duration was 5 (5) years and the mean (SD) baseline EDSS score was 2 (0.8). Baseline characteristics were compared in patients with and without MRI follow-up data. No significant differences between these two groups were observed in sex ratio, age, education, QoL, IQ scores (verbal, performance or total IQ) or sc IFN $\beta$-1a dose. Significant differences were seen between patients with and without MRI follow-up for: impaired performance on $\geq 3$ tests $(12.1 \%$ vs 26.5\%; $P=0.0003$ ); disease duration (mean [SD]: 4.8 [4.9] vs 3.2 [4.1] years; $P<0.0001$ ); EDSS score (mean [SD]: 2.0 [0.8] vs 1.7 [1.0]; $P=0.0037$ ) and HDRS score (mean [SD]: 8.0 [5.2] vs $6.1[4.6] ; P=0.0002)$.

\section{Effect of sc IFN $\beta$-1a on MRI outcomes (pooled data)}

At Year 3, both T2 lesion and T1 Gd+ lesion volumes were significantly lower than at baseline (Table 1). The mean (SD) absolute decrease in T2 lesion volume was $644.2(3072.1) \mathrm{mm}^{3}$ and the mean percentage change was $-7.6 \%(P<0.0001$ vs baseline; both measures). T1 Gd+ lesion volume decreased by $48.2(269.3) \mathrm{mm}^{3}(P=0.0034$ vs baseline), and mean percentage change from baseline was $-60.5 \%(P<0.0001)$. T1 black hole $(\mathrm{BH})$ volume did not decrease significantly from baseline to Year 3 .

The proportion of patients who were free from new $\mathrm{T} 2$ lesions, new $\mathrm{T} 1 \mathrm{Gd}+$ lesions and new $\mathrm{BH}$ at all time points from baseline to Year 3 were: $51.2 \%$ (84/164), $83.8 \%(134 / 160)$ and $68.5 \%(111 / 162)$, respectively. When only scans from baseline and Year 3 were considered, $79.9 \%(131 / 164)$ of patients, $93.1 \%(149 / 160)$ and $88.3 \%(144 / 163)$ of patients were free from new T2 lesions, new $\mathrm{T} 1 \mathrm{Gd}+$ lesions and new $\mathrm{BH}$, respectively.

\section{Comparison of effects of sc IFN $\beta-1 a, 44$ and $22 \mu \mathrm{g}$, on MRI outcomes}

No significant differences between the two dosage groups were seen in $\mathrm{T} 2, \mathrm{~T} 1 \mathrm{Gd}+$ or $\mathrm{BH}$ lesion volumes at any timepoint. The number of new T2, T1 Gd+ and BH lesions did not differ between dosage groups at any time point (Year 1, 2 or 3) nor was there any significant difference in the cumulative number of new lesions over the 3 years of follow-up (data not shown).

Treatment with IFN $\beta$-1a, $44 \mu \mathrm{g}$ sc tiw, was associated with a significantly greater percentage decrease in T2 lesion volume from baseline to Year 3 than that seen with the $22 \mu \mathrm{g}$ sc tiw dosage $(P=0.025$; Table 2$)$. The 
Table 1 Change in MRI parameters from baseline to Year 3 (pooled treatment groups)

\begin{tabular}{|c|c|c|c|c|c|c|}
\hline \multirow[b]{3}{*}{ Lesion volume, $\mathrm{mm}^{3}$} & \multicolumn{6}{|c|}{ MRI Parameter } \\
\hline & \multicolumn{2}{|c|}{ T2 lesions } & \multicolumn{2}{|c|}{$\mathrm{T} 1 \mathrm{Gd}+$ lesions } & \multicolumn{2}{|c|}{ T1 black holes } \\
\hline & Baseline & Year 3 & Baseline & Year 3 & Baseline & Year 3 \\
\hline N & 158 & 158 & 154 & 154 & 156 & 156 \\
\hline Mean (SD) & 5990.1 (7111.6) & 5345.9 (6755.3) & $73.8(252.1)$ & $25.6(125.5)$ & $1263.1(2430.6)$ & $1185.4(2520.7)$ \\
\hline Median & 3378.5 & 2825.0 & 0.0 & 0.0 & 436.3 & 341.9 \\
\hline Q1, Q3 & $1052.9,7358.5$ & $782.0,6918.5$ & $0.0,0.0$ & $0.0,0.0$ & $76.5,1189.2$ & $67.9,1160.0$ \\
\hline \multicolumn{7}{|l|}{ Absolute change, $\mathrm{mm}^{3}$} \\
\hline $\mathrm{N}$ & \multicolumn{2}{|c|}{158} & \multicolumn{2}{|c|}{154} & \multicolumn{2}{|c|}{156} \\
\hline Mean (SD) & \multicolumn{2}{|c|}{$-644.2(3072.1)$} & \multicolumn{2}{|c|}{$-48.2(269.3)^{*}$} & \multicolumn{2}{|c|}{$-77.7(1056.8)$} \\
\hline Median & \multicolumn{2}{|c|}{-135.6} & \multicolumn{2}{|c|}{0.0} & \multicolumn{2}{|c|}{0.0} \\
\hline Q1, Q3 & \multicolumn{2}{|c|}{$-719.8,86.7$} & \multicolumn{2}{|c|}{$0.0,0.0$} & \multicolumn{2}{|c|}{$-89.5,73.4$} \\
\hline \multicolumn{7}{|l|}{ Percentage change ${ }^{\dagger}$} \\
\hline N & \multicolumn{2}{|c|}{158} & \multicolumn{2}{|c|}{34} & \multicolumn{2}{|c|}{132} \\
\hline Mean (SD) & \multicolumn{2}{|c|}{$-7.6(34.1)^{c}$} & \multicolumn{2}{|c|}{$-60.5(149.4)^{\ddagger}$} & \multicolumn{2}{|c|}{$0.3(67.8)$} \\
\hline Median & \multicolumn{2}{|c|}{-7.3} & \multicolumn{2}{|c|}{-100.0} & \multicolumn{2}{|c|}{-4.7} \\
\hline Q1, Q3 & \multicolumn{2}{|c|}{$-23.8,4.0$} & \multicolumn{2}{|c|}{$-100.0,-100.0$} & \multicolumn{2}{|c|}{$-32.1,19.5$} \\
\hline
\end{tabular}

$\mathrm{Gd}+$, gadolinium-enhancing; IFN, interferon.

${ }^{*} P=0.0034$ vs baseline; Wilcoxon signed rank test.

${ }^{\dagger}$ Percentage change was not calculated for patients with a lesion volume of $0 \mathrm{~mm}^{3}$ at baseline.

${ }^{\ddagger} P<0.0001$ vs baseline; Wilcoxon signed rank test.

percentage and absolute change in $\mathrm{BH}$ volume from baseline to Year 3 also differed significantly between dosage groups, increasing in the $22 \mu \mathrm{g}$ group and decreasing in the $44 \mu \mathrm{g}$ group (percentage change: $P=$ 0.002; absolute change: $P=0.017$ for comparison of doses). There was no significant difference in change in $\mathrm{T} 1 \mathrm{Gd}+$ lesion volume over time between dosage groups. The proportion of patients who had a decrease in T2 lesion volume between baseline and Year 3 was significantly greater in the $44 \mu$ g group $(72.1 \%)$ than in the 22 $\mu$ group $(56.9 \% ; P=0.047$; Figure 1$)$. A similar trend was seen for the proportion of patients with a decrease in $\mathrm{BH}$ volume (44 $\mu \mathrm{g}$ : 54.1\%; $22 \mu \mathrm{g}: 39.4 \%$; $P=0.067$; Figure 1). Multivariate logistic regression showed that treatment with sc IFN $\beta-1 \mathrm{a} 44 \mu \mathrm{g}$ predicted a decrease in $\mathrm{T} 2$ lesion volume and $\mathrm{BH}$ lesion volume compared with the $22 \mu \mathrm{g}$ dose (Table 3).

\section{Cognitive outcomes and MRI measures of disease}

Of the patients for whom follow-up data were available at Year 3, 11.8\% (18/152) had impaired performance on $\geq 3$ cognitive tests (i.e. were cognitively impaired). The proportion of patients with cognitive impairment was significantly lower in the $44 \mu \mathrm{g}$ group than in the $22 \mu \mathrm{g}$ group (6.0\% vs $18.8 \%, P=0.015)$.

The proportion of patients with a decrease in T2 or $\mathrm{BH}$ volume did not differ significantly between those with or without cognitive impairment $(P=0.236$ for T2 lesion volume; $P=0.892$ for $\mathrm{BH}$ volume). No significant effect of sc IFN $\beta$-1a dose was observed.
Patients with $\geq 2$ impaired cognitive tests at baseline were less likely to have decreased T2 lesion volume over the course of the study compared with patients with $<2$ impaired tests $(P=0.034$; Table 4$)$. There were no other differences in MRI outcomes over 3 years between patients with $<2$ or $\geq 2$ impaired tests at baseline.

\section{Predictors of clinical, MRI and cognitive outcomes at Year 3}

Predictors of clinical, MRI and cognitive outcomes at Year 3 were identified using multivariate logistic regression. T1 Gd+ lesion number at baseline was a predictor of being disease-free at Year 3 (odds ratio [OR]: 0.29, 95\% confidence interval [CI]: 0.08-0.95). Baseline EDSS score (OR: 0.53, 95\% CI: 0.33-0.86), baseline T2 lesion volume (OR: 1.01, 95\% CI: 1.00-1.01) and disease-free status over 3 years (OR: 0.31, 95\% CI: 0.00-0.84) predicted the development of new BH over 3 years. Baseline T2 lesion volume (OR: 1.01, 95\% CI: 1.00-1.01) and new T2 lesions over 3 years (OR: 6.68, 95\% CI: 2.0921.52) predicted the development of new $\mathrm{Gd}+$ lesions. Predictors for the presence or absence of new T2 lesions over 3 years were disease duration (OR: 0.91, 95\% CI: 0.84-0.98), and the presence of new $\mathrm{Gd}+$ lesions over 3 years (OR: 4.18, 95\% CI: 1.57-11.19).

Treatment with the $44 \mu \mathrm{g}$ dose of sc IFN $\beta-1 \mathrm{a}$, and higher verbal IQ score at baseline, predicted better cognitive outcomes at Year 3 (Table 3). Higher baseline T2 lesion volume was predictive of cognitive impairment ( $\geq 3$ impaired tests) at Year 3 (Table 3). 


\begin{tabular}{|c|c|c|c|c|c|c|}
\hline & \multicolumn{6}{|c|}{ MRI Parameter } \\
\hline & \multicolumn{2}{|c|}{ T2 lesion volume } & \multicolumn{2}{|c|}{$\mathrm{T} 1 \mathrm{Gd}+$ lesion volume } & \multicolumn{2}{|c|}{ T1 black hole volume } \\
\hline & IFN $\beta-1 \mathrm{a}, 22 \mu \mathrm{g}$ sc tiw & IFN $\beta-1 \mathrm{a}, 44 \mu \mathrm{g}$ sc tiw & IFN $\beta-1 \mathrm{a}, 22 \mu \mathrm{g} s c$ tiw & IFN $\beta-1 \mathrm{a}, 44 \mu \mathrm{g}$ sc tiw & IFN $\beta-1 a, 22 \mu \mathrm{g} s c$ tiw & IFN $\beta-1 \mathrm{a}, 44 \mu \mathrm{g} s \mathrm{sc}$ tiw \\
\hline \multicolumn{7}{|c|}{ Absolute change, $\mathrm{mm}^{3}$} \\
\hline N & 72 & 86 & 70 & 84 & 71 & 85 \\
\hline Mean (SD) & $-174.9(1609.8)$ & $-1037.2(3863.3)$ & $-23.5(198.5)$ & $-68.8(316.3)$ & $64.5(608.5)$ & $-196.5(1311.9)$ \\
\hline Median & -81.6 & -169.7 & 0.0 & 0.0 & 0.0 & -25.3 \\
\hline Q1, Q3 & $-654.5,126.8$ & $-1133.3,13.5$ & $0.0,0.0$ & $0.0,0.0$ & $-40.3,92.5$ & $-209.4,26.8$ \\
\hline$P$ value & \multicolumn{2}{|c|}{0.092} & \multicolumn{2}{|c|}{0.472} & \multicolumn{2}{|c|}{0.017} \\
\hline \multicolumn{7}{|c|}{ Percentage change } \\
\hline $\mathrm{N}$ & 72 & 86 & $15^{*}$ & $19^{*}$ & $59^{*}$ & $73^{*}$ \\
\hline Mean (SD) & $-4.5(27.3)$ & $-10.2(38.9)$ & $-54.2(177.5)$ & $-65.4(127.9)$ & $10.3(49.3)$ & $-7.8(79.1)$ \\
\hline Median & -3.4 & -12.1 & -100.0 & -100.0 & 1.5 & -16.1 \\
\hline Q1, Q3 & $-14.5,4.3$ & $-30.6,2.8$ & $-100.0,-100.0$ & $-100.0,-100.0$ & $-10.6,23.2$ & $-50.5,19.0$ \\
\hline$P$ value & \multicolumn{2}{|c|}{0.025} & \multicolumn{2}{|c|}{0.495} & \multicolumn{2}{|c|}{0.002} \\
\hline
\end{tabular}

Gd+, gadolinium-enhancing; IFN, interferon; sc, subcutaneously; tiw, three times weekly.

*Percentage change was not calculated for patients with a lesion volume of $0 \mathrm{~mm}^{3}$ at baseline. 


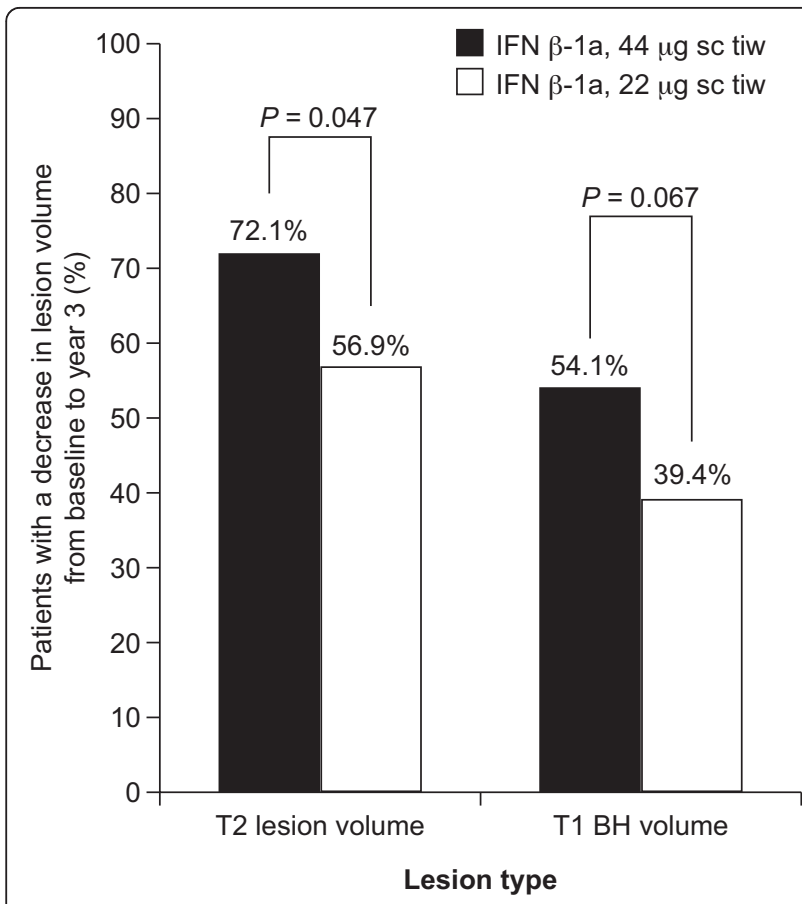

Figure 1 Proportion of patients with a decrease in T2 lesion volume or T1 black hole (BH) volume from baseline to Year 3, by interferon (IFN) $\beta$-1a dose group. Sc, subcutaneously; tiw, three times weekly.

\section{MRI, QoL and psychosocial outcomes}

The proportion of patients with a clinically relevant change in QoL (MSQoL-54 total score only) from baseline to Year 3 was lower in patients who had a decrease in T2 lesion volume over the same interval (12.4\%) than in those with stable/increased T2 lesion volume (29.4\%; $P=0.009$ ). No difference was seen in the proportion of

Table 3 Predictors of cognitive impairment at Year 3, defined as impaired performance on $\geq 3$ cognitive tests (multivariate logistic regression)

\begin{tabular}{|c|c|c|}
\hline & Odds ratio & $95 \% \mathrm{Cl}$ \\
\hline \multicolumn{3}{|l|}{ Stable/increased T2 lesion volume over 3 years } \\
\hline Treatment with sc IFN $\beta$-1a $44 \mu \mathrm{g}$ tiw & 0.45 & $0.23-0.91$ \\
\hline Baseline $\mathrm{BH}$ lesion volume & 1.01 & $1.00-1.01$ \\
\hline Number of new $\mathrm{T} 2$ lesions & 1.13 & $1.02-1.26$ \\
\hline \multicolumn{3}{|l|}{ Stable/increased BH volume over 3 years } \\
\hline Treatment with sc IFN $\beta$-1a $44 \mu \mathrm{g}$ tiw & 0.46 & $0.23-0.92$ \\
\hline ESS score at baseline & 0.82 & $0.69-0.98$ \\
\hline Presence of new $\mathrm{BH}$ over 3 years & 3.21 & $1.52-6.75$ \\
\hline \multicolumn{3}{|l|}{ Three or more impaired cognitive tests at Year 3} \\
\hline Baseline T2 lesion volume & 1.01 & $1.00-1.01$ \\
\hline Verbal $I^{*}$ & 0.92 & $0.87-0.98$ \\
\hline IFN $\beta-1 \mathrm{a}, 44 \mu \mathrm{g}$ sc tiw & 0.31 & $0.10-0.98$ \\
\hline
\end{tabular}

$\mathrm{Cl}$, confidence interval; IFN, interferon; IQ, intelligence quotient; $\mathrm{SC}$, subcutaneously; tiw, three times weekly.

*Higher score denotes superior outcome. patients with or without a decrease in $\mathrm{BH}$ volume. Analyses of fatigue, depressive symptoms and social functioning showed that the proportion of patients with clinically relevant changes in these outcomes did not differ according to whether or not $\mathrm{T} 2$ or $\mathrm{BH}$ lesion volume decreased over 3 years (data not shown).

Multivariate analyses confirmed that a decrease in T2 lesion volume was a significant predictor of stable MSQoL-54 total score (OR: 0.4, 95\% CI: 0.16-1.00). Higher baseline FIS (OR: 1.04, 95\% CI: 1.01-1.08) and total MSQoL-54 (OR: 1.08, 95\% CI: 1.03-1.12) scores were predictive of clinically relevant changes in MSQoL54 scores from baseline to Year 3 .

\section{Discussion}

The beneficial effects of sc IFN $\beta-1 \mathrm{a}$ on MRI measures of disease in patients with RRMS are well recognized. In this observational study, such effects were seen in patients being treated and assessed under normal clinical practice conditions, strengthening our results. Here we demonstrated significant effects of sc IFN $\beta-1$ a on T2 and T1 Gd + lesion volumes over 3 years in a large cohort of patients with mild physical disability (mean EDSS score: 2.0). Furthermore, most patients remained free from new T1 $\mathrm{Gd}+, \mathrm{T} 2$ and $\mathrm{BH}$ lesions over the course of the study. A dose-dependent effect was seen in several MRI outcomes, with the $44 \mu \mathrm{g}$ dose having a more pronounced benefit than the $22 \mu \mathrm{g}$ dose. Treatment with the $44 \mu \mathrm{g}$ dose of IFN $\beta$-1a also predicted better cognitive outcomes at Year 3. T2 lesion volume was found to be associated with poor cognitive and QoL outcomes.

Over the 3-year study, sc IFN $\beta$-1a treatment was associated with a significant reduction in $\mathrm{T} 1 \mathrm{Gd}+$ and T2 lesion volumes, with a significant benefit of the 44 $\mu \mathrm{g}$ dose demonstrated for T2 lesion volume. These findings are consistent with those of the pivotal PRISMS study, in which sc IFN $\beta-1$ a reduced T2 BOD and CUA lesion number over 2 years of treatment, with a dosedependent effect on T2 lesion number and activity [4,7]. Our data confirm that sc IFN $\beta-1$ a has beneficial effects on MRI measures of disease in this cohort of mildly disabled patients with RRMS. It is interesting that no dose effect was observed for T1 Gd+ lesions. As Gd+ lesions are new lesions, it is possible that the lower $22 \mu \mathrm{g}$ dose of IFN $\beta-1 \mathrm{a}$ is able to inhibit initial inflammatory processes in these patients in the early stages of disease. Indeed, an effect of sc IFN $\beta$-1a on active MRI lesions was reported at Month 2 in the PRISMS study, during which patients received lower doses of IFN $\beta$-1a during titration up to the $44 \mu \mathrm{g}$ tiw dose [4]. The dose effect may, however, become evident when assessing longerterm MRI measures such as T2 lesion volume, which capture both old and new lesions. It is possible that newer lesions are more susceptible to the effects of sc 
Table 4 Association between changes in T2 lesion volume over 3 years and baseline cognitive impairment

\begin{tabular}{|c|c|c|c|c|}
\hline & & \multicolumn{2}{|c|}{$\geq 2$ impaired cognitive tests at baseline } & \multirow[b]{2}{*}{$P$-value } \\
\hline & & No $(n=114)$ & Yes $(n=44)$ & \\
\hline \multirow[t]{2}{*}{ Stability or increase of T2 lesion volume, n (\%) } & Yes & $34(29.8)$ & $21(47.7)$ & 0.034 \\
\hline & No & $80(70.2)$ & $23(52.3)$ & \\
\hline
\end{tabular}

IFN $\beta$-1a than more established, chronic and inactive lesions.

The presence of BH indicates areas of axonal loss (neurodegeneration). Although we did not find a significant effect on $\mathrm{BH}$ lesion volume from baseline to Year 3 in the whole cohort, a significant difference between the two treatment groups was seen regarding the change in $\mathrm{BH}$ volume: $\mathrm{BH}$ volume increased in the $22 \mu \mathrm{g}$ group, but decreased in the $44 \mu$ g group over the 3 -year study. Whether IFN $\beta-1 \mathrm{a}$ is neuroprotective is still a subject of some debate; however, our findings may suggest that the $44 \mu \mathrm{g}$ dose of sc IFN $\beta-1$ a could have neuroprotective effects. This is a particularly interesting finding as $\mathrm{BH}$ were not measured in earlier studies of DMDs, and hence how $\mathrm{BH}$ are associated with long-term treatmentrelated clinical outcomes is not known [8].

At Year 3, only $11.8 \%$ of patients had impaired performance on $\geq 3$ cognitive tests. This is slightly lower than the proportion reported in the parent COGIMUS study [17], which may reflect differences between patients who underwent MRI scans and those who did not. Treatment with the $44 \mu \mathrm{g}$ dose of IFN $\beta$-1a was associated with better cognitive outcomes, whereas higher T2 lesion load predicted cognitive decline. An association between T2 lesions and cognitive impairment has been reported previously $[16,25-28]$. As we saw a clear, dose-related effect of treatment on MRI measures and an association between $\mathrm{T} 2$ lesions and cognition, it is interesting to speculate on how the effect on different MRI lesion types may translate into cognitive benefits. Loss of axons (BH) could result in loss of neuronal connectivity, whereas T2 lesions might indicate reduced efficiency of neurotransmission owing to myelin degradation. Mapping the distribution of MS lesions and assessment of those in regions known to govern cognitive processes could provide further insights into how the effects of IFN $\beta$-1a treatment on MRI parameters are associated with cognitive benefits. Metabolic studies may also further explain the relation between treatment effects on MRI parameters and cognitive outcomes. In one study using positron emission tomography, the cortical rate of glucose metabolism was shown to be reduced significantly in patients with MS compared with healthy controls, and was inversely correlated with T2 BOD and cognitive performance [29]. White matter lesions could denervate cortical areas and be responsible for the observed reduction in cortical glucose metabolism resulting in clinical symptoms.
Decreased T2 lesion volume also predicted better QoL scores. Associations between MRI parameters (white matter lesion loads and brain atrophy) and QoL outcomes have been described in a cross-sectional analysis of patients with MS [30]. Here, we have assessed longitudinal treatment effects on QoL and MRI disease measures. Together, our and previous observations suggest that treatment-related reductions in MS lesion burden may have a positive effect on patients' daily lives. It is also possible that starting treatment may have positive psychological effects due to the patient's expectation that their treatment will reduce relapses and protect against worsening disability and cognitive impairment that lead to improved QoL. No associations were found between MRI measures and fatigue, depressive symptoms or social functioning in our analysis. However, higher fatigue at baseline did predict worsening QoL. These findings demonstrate the complexity of MS and the importance of measuring both pathological and symptomatic parameters to understand fully the impact of MS on the patient.

The limitations of this analysis should be considered. This was a post hoc analysis of data from an observational study, and there was no untreated comparator group; treatment effects should therefore be interpreted with caution. Consequently, differences observed between the lower and higher doses of sc IFN $\beta$-1a may have been affected by selection bias, although treatment groups were balanced with regard to main demographic variables. In addition, MRI data at Year 3 were missing for approximately half of the patients with baseline MRI data. Furthermore, among those patients from whom MRI data were collected over 3 years' follow-up, data for some parameters were missing. Despite this, we collected MRI and cognition data for $>300$ patients at baseline and for $>150$ patients at Year 3, making this a valuable data set, particularly considering the mild disability and short disease duration in this cohort. Notably, there were some important differences between patients with and without 3-year MRI data, including the proportion who had cognitive impairment, and in EDSS scores. This finding may have influenced the other results reported here and highlights the difficulties that can be encountered with data collection in longitudinal studies. Concerning MRI parameters, we did not assess cortical pathology (inflammatory lesions and atrophy), which has recently been shown to contribute considerably to neuropsychological symptoms in MS 
$[31,32]$. As the importance of cortical pathology in MS, particularly with respect to cognitive outcomes, emerged after the start of the COGIMUS study it was not possible to include such assessments in this analysis. In addition, it should be noted that $\mathrm{Gd}+$ lesions can only be detected for a time period of around 1 month at most, so it is possible that some of these lesions may not have been counted due to the scans being performed annually; however, this interval was dictated by routine practice due to the observational nature of the study. Finally, due to low patient numbers, it was necessary to define cognitive impairment as impaired performance on $\geq 2$ cognitive tests to investigate associations between MRI parameters and cognitive status, whereas the definition in the parent COGIMUS study required impairment on $\geq 3$ tests.

\section{Conclusions}

These findings demonstrate that sc IFN $\beta-1 \mathrm{a}$ has a beneficial effect on MRI measures of disease in a population of patients with early RRMS and mild physical disability in a normal clinical setting. A dose effect was seen on MRI outcomes, notably on $\mathrm{BH}$, an indicator of neurodegeneration, and was greater with the $44 \mu \mathrm{g}$ than with the $22 \mu \mathrm{g}$ dose of sc IFN $\beta-1 \mathrm{a}$. T2 lesion load and treatment with the higher dose of sc IFN $\beta$-1a predicted preserved cognitive function over the 3 -year study. These results confirm the efficacy of sc IFN $\beta$-1a in RRMS and suggest that effects on MRI measures may underlie potential cognitive and QoL benefits of this treatment.

\section{List of abbreviations \\ BH: black hole; BOD: burden of disease; Cl: confidence interval; CUA: combined unique active; DMD: disease-modifying drug; EDSS: Expanded Disability Status Scale; ESS: Environmental Status Scale; FIS: Fatigue Impact Scale; FOV: field of view; Gd+: gadolinium-enhancing; HDRS: Hamilton Depression Rating Scale; IFN: interferon; im: intramuscular; IQ: intelligence quotient; MRI: magnetic resonance imaging; MS: multiple sclerosis; MSQoL- 54: Multiple Sclerosis Quality of Life-54 [questionnaire]; OR: odds ratio; QoL: quality of life; RRMS: relapsing-remitting multiple sclerosis; sc: subcutaneous (ly); SD: standard deviation; tiw: three times weekly}

\section{Acknowledgements and funding}

This study was supported by a grant from the European Biomedical Foundation. The authors thank Adam McGechan and Reza Sayeed for Caudex Medical, Oxford, UK (supported by Merck Serono S.A. - Geneva, Switzerland, a branch of Merck Serono S.A., Coinsins, Switzerland, an affiliate of Merck KGaA, Darmstadt, Germany), for assistance with the preparation of the outline of the article and incorporating author comments, and thank Stephen Smith and Andrea Plant of Caudex Medical, Oxford, UK, for assistance with drafting the manuscript and incorporating author comments. The manuscript has been reviewed by Merck Serono for the limited purpose of providing complete and balanced medical/scientific information and to ensure that the publication is objective and scientifically/medically accurate. The views and opinions described herein do not necessarily reflect those of Merck Serono. The COGIMUS study group comprises the following investigators: Catania: F Patti, S Lo Fermo, R Vecchio, D Maimone, S Messina; Rome: C Gasperini; Naples: V Orefice, V Brescia Morra, C Florio; Florence: MP Amato, B Goretti, E Portaccio, V Zipoli; Orbassano: A Bertolotto; Messina: P Bramanti, E Sessa; Rome Tor Vergata: D Centonze; Palermo: S Cottone, G Salemi; Prato: M Falcini; Padova: P Gallo, P Perini; Udine: GL Gigli; Macerata: G Giuliani; Cefalù: LME Grimaldi; Pisa: L Murri; Chieti: A Lugaresi; Novara: F Monaco;
Fidenza: E Montanari; Reggio Emilia: L Motti; Terni: S Neri; Potenza: M Paciello; Ancona: L Provinciali; Ascoli Piceno: M Ragno; Sassari: G Rosati; Pozzilli: S Ruggieri; Ferrara: MR Tola, L Caniatti; Roma Gemelli: P Tonali, AP Batocchi; Bari: M Trojano, E Di Monte, MF De Caro; Gallarate: A Ghezzi, M Zaffaroni; Arezzo: P Zolo; Trieste: M Zorzon; Fermo: M Signorino; Milan: E Scarpini; Torino: L Durelli; L'Aquila: A Carolei, R. Totaro; Avellino: D Spitaleri; La Spezia: A Tartaglione.

\section{Author details}

'National Neurological Institute, C Mondino Foundation, IRCCS, Via Ferrata, I27100, Pavia, Italy. ${ }^{2}$ European Biomedical Foundation Onlus, via Nizza 53, 00198, Rome, Italy. ${ }^{3}$ Department of Neurology, University of Florence, Viale Morgagni 85, 50134 Florence, Italy. ${ }^{4}$ Department of Neuroscience and Rehabilitation, Azienda Università-Ospedale, Corso Giovecca 203, 44100 Ferrara, Italy. ${ }^{5}$ Department of Neurological and Psychiatric Sciences, University of Bari, Piazza Giulio Cesare, 70124 Bari, Italy. ${ }^{6}$ European Biomedical Foundation, Onlus, Rome, Italy. ${ }^{7}$ RCCS Foundazione Santa Lucia, Via Ardeatina 306, 00179 Rome, Italy. ${ }^{8}$ Biostructure and Bioimaging Institute, National Research Council, Via Pansini 5, 80131 Naples, Italy. ${ }^{9}$ Opera S.r.l., Via Sampierdarena 33, 16149 Genova, Italy. ${ }^{10}$ Department of Neurology, Multiple Sclerosis Centre Sicilia Region, First Neurology Clinic, University Hospital, Via Santa Sofia 78, 95123 Catania, Italy.

\section{Authors' contributions}

SB participated in the design of the study, performed the processing of study data and helped to draft the manuscript. EG performed quantitative analysis of neuroimaging and processing of study data, and helped to draft the manuscript. MPA, MRT, and MT participated in study coordination (patient recruitment) and the collection of clinical data. SG performed quantitative analysis of neuroimaging and helped to draft the manuscript. $\mathrm{GL}$ and $\mathrm{MQ}$ participated in the design of the study and performed the processing of study data. OP performed the statistical analysis and helped to draft the manuscript. FP participated in the design of the study and study coordination (patient recruitment). All authors read and approved the final manuscript.

\section{Competing interests}

SB has no competing interests to declare.

EG has no competing interests to declare.

MPA has received personal compensation and research grants from Merck Serono, Bayer Schering, Biogen and sanofi-aventis; and financial support for research activities from Merck Serono, Bayer Schering, Biogen and sanofiaventis.

MRT has received research funding from sanofi-aventis and compensation for consultancy or speaking from Biogen, sanofi-aventis, Merck Serono and Novartis.

MT has received honoraria for consultancy or speaking from Biogen, sanofiaventis, Merck Serono and Bayer-Schering; and research grants from Merck Serono and Biogen.

SG has no competing interests to declare.

GL has no competing interests to declare.

MQ has no competing interests to declare.

$\mathrm{OP}$ has no competing interests to declare.

FP has received research funding from the University of Catania and

Fondazione Italiana Sclerosi Multipla, and personal compensation from Bayer Schering, Biogen-Dompè, Merck Serono and Novartis; and has served on scientific advisory boards for Bayer Schering, Merck Serono, Novartis and Biogen Idec.

Received: 9 June 2011 Accepted: 14 October 2011

Published: 14 October 2011

\section{References}

1. McDonald WI, Compston A, Edan G, Goodkin D, Hartung HP, Lublin FD, McFarland HF, Paty DW, Polman CH, Reingold SC, Sandberg-Wollheim M, Sibley W, Thompson A, van den Noort S, Weinshenker BY, Wolinsky JS: Recommended diagnostic criteria for multiple sclerosis: guidelines from the International Panel on the Diagnosis of Multiple Sclerosis. Ann Neurol 2001, 50:121-127.

2. IFNB Multiple Sclerosis Study Group: Interferon beta- $1 \mathrm{~b}$ is effective in relapsing-remitting multiple sclerosis. I Clinical results of a multicenter, 
randomized, double-blind, placebo-controlled trial. Neurology 1993, 43:655-661.

3. Johnson KP, Brooks BR, Cohen JA, Ford CC, Goldstein J, Lisak RP, Myers LW, Panitch HS, Rose JW, Schiffer RB: Copolymer 1 reduces relapse rate and improves disability in relapsing-remitting multiple sclerosis: results of a phase III multicenter, double-blind placebo-controlled trial. Neurology 1995, 45:1268-1276.

4. Li DK, Paty DW, UBC MS/MRI Analysis Research Group, PRISMS Study Group: Magnetic resonance imaging results of the PRISMS trial: a randomized, double-blind, placebo-controlled study of interferon-beta1a in relapsingremitting multiple sclerosis. Ann Neurol 1999, 46:197-206.

5. Simon JH, Jacobs LD, Campion M, Wende K, Simonian N, Cookfair DL, Rudick RA, Herndon RM, Richert JR, Salazar AM, Alam JJ, Fischer JS, Goodkin DE, Granger CV, Lajaunie M, Martens-Davidson AL, Meyer M, Sheeder J, Choi K, Scherzinger AL, Bartoszak DM, Bourdette DN, Braiman J, Brownscheidle CM, Whitham RH: Magnetic resonance studies of intramuscular interferon beta-1a for relapsing multiple sclerosis. Ann Neurol 1998, 43:79-87.

6. De Stefano N, Curtin F, Stubinski B, Blevins G, Drulovic J, Issard D, Shotekov P, Gasperini C, IMPROVE Study Investigators: Rapid benefits of a new formulation of subcutaneous interferon beta-1a in relapsingremitting multiple sclerosis. Mult Scler 2010, 16:888-892.

7. PRISMS Study Group: Randomised double-blind placebo-controlled study of interferon beta-1a in relapsing/remitting multiple sclerosis. Lancet 1998, 352:1498-1504

8. Kappos L, Traboulsee A, Constantinescu C, Erälinna JP, Forrestal F, Jongen P, Pollard J, Sandberg-Wollheim M, Sindic C, Stubinski B, Uitdehaag B, Li D: Long-term subcutaneous interferon beta-1a therapy in patients with relapsing-remitting MS. Neurology 2006, 67:944-953.

9. Barkhof F: The clinico-radiological paradox in multiple sclerosis revisited. Curr Opin Neurol 2002, 15:239-245.

10. Zivadinov R, Leist TP: Clinical-magnetic resonance imaging correlations in multiple sclerosis. J Neuroimaging 2005, 15(4 Suppl):10S-21S.

11. Amato MP, Zipoli V, Portaccio E: Multiple sclerosis-related cognitive changes: a review of cross-sectional and longitudinal studies. J Neurol Sci 2006, 245:41-46.

12. Glanz BI, Healy BC, Rintell DJ, Jaffin SK, Bakshi R, Weiner HL: The association between cognitive impairment and quality of life in patients with early multiple sclerosis. J Neurol Sci 2010, 290:75-79.

13. Rao SM, Leo GJ, Ellington L, Nauertz T, Bernardin L, Unverzagt F: Cognitive dysfunction in multiple sclerosis. II. Impact on employment and social functioning. Neurology 1991, 41:692-696.

14. Lazeron RH, de Sonneville LM, Scheltens P, Polman CH, Barkhof F: Cognitive slowing in multiple sclerosis is strongly associated with brain volume reduction. Mult Scler 2006, 12:760-768

15. Rovaris M, Filippi M: MRI correlates of cognitive dysfunction in multiple sclerosis patients. J Neurovirol 2000, 6(Suppl 2):S172-S175.

16. Patti F, Amato M, Trojano M, Bastianello S, Tola MR, Goretti B, Caniatti L, Di Monte E, Ferrazza P, Brescia Morra V, Lo Fermo S, Picconi O, Luccichenti G, COGIMUS Study Group: Cognitive impairment and its relation with disease measures in mildly disabled patients with relapsing-remitting multiple sclerosis: baseline results from the Cognitive Impairment in Multiple Sclerosis (COGIMUS) study. Mult Scler 2009, 15:779-788

17. Patti F, Amato MP, Bastianello S, Caniatti L, Di Monte E, Ferrazza P, Goretti B, Gallo P, Morra VB, Lo Fermo S, Picconi O, Tola MR, Trojano M, COGIMUS Study Group: Effects of immunomodulatory treatment with subcutaneous interferon beta-1a on cognitive decline in mildly disabled patients with relapsing-remitting multiple sclerosis. Mult Scler 2010, 16:68-77.

18. Patti F, Amato MP, Bastianello S, Caniatti L, Di Monte E, Lijoi F, Goretti B, Messina S, Picconi O, Tola MR, Trojano M: Subcutaneous interferon beta1a has a positive effect on cognitive performance in mildly disabled patients with relapsing-remitting multiple sclerosis: 2-year results from the COGIMUS study. Ther Adv Neurol Disorders 2009, 2:67-77.

19. Amato MP, Portaccio E, Goretti B, Zipoli V, Ricchiuti L, De Caro MF, Patti F, Vecchio R, Sorbi S, Trojano M: The Rao's Brief Repeatable Battery and Stroop Test: normative values with age, education and gender corrections in an Italian population. Mult Scler 2006, 12:787-793.

20. Colombo L, Sartori G, Brivio C: La stima del quoziente intellettivo tramite I'applicazione del TIB (Test di Intelligenza Breve). G Ital Psicol 2002, 3:613-637.
21. Fisk JD, Ritvo PG, Ross L, Haase DA, Marrie TJ, Schlech WF: Measuring the functional impact of fatigue: initial validation of the fatigue impact scale. Clin Infect Dis 1994, 18(Suppl 1):S79-S83.

22. Hamilton M: A rating scale for depression. I Neurol Neurosurg Psychiatry 1960, 23:56-62.

23. Mellerup E, Fog T, Raun N, Colville P, De Rham B, Hannah B, Kurtzke J: The socio-economic scale. Acta Neurol Scand 1981, 64:130-138.

24. Rudick RA, Miller D, Hass S, Hutchinson M, Calabresi PA, Confavreux C, Galetta SL, Giovannoni G, Havrdova E, Kappos L, Lublin FD, Miller DH, O'Connor PW, Phillips JT, Polman CH, Radue EW, Stuart WH, Wajgt A, Weinstock-Guttman B, Wynn DR, Lynn F, Panzara MA, AFFIRM and SENTINEL Investigators: Health-related quality of life in multiple sclerosis: effects of natalizumab. Ann Neurol 2007, 62:335-346.

25. Summers M, Swanton J, Fernando K, Dalton C, Miller DH, Cipolotti L, Ron MA: Cognitive impairment in multiple sclerosis can be predicted by imaging early in the disease. I Neurol Neurosurg Psychiatry 2008, 79:955-958.

26. Deloire MS, Salort E, Bonnet M, Arimone $Y$, Boudineau M, Amieva $H$, Barroso B, Ouallet JC, Pachai C, Galliaud E, Petry KG, Dousset V, Fabrigoule $C$, Brochet B: Cognitive impairment as marker of diffuse brain abnormalities in early relapsing remitting multiple sclerosis. I Neurol Neurosurg Psychiatry 2005, 76:519-526.

27. Patti F, Failla G, Ciancio MR, L'Episcopo MR, Reggio A: Neuropsychological, neuroradiological and clinical findings in multiple sclerosis. A 3 year follow-up study. Eur J Neurol 1998, 5:283-286.

28. Rudick RA, Lee JC, Simon J, Fisher E: Significance of T2 lesions in multiple sclerosis: a 13-year longitudinal study. Ann Neurol 2006, 60:236-242.

29. Blinkenberg M, Rune K, Jensen CV, Ravnborg M, Kyllingsbaek S, Holm S, Paulson OB, Sørensen PS: Cortical cerebral metabolism correlates with MRI lesion load and cognitive dysfunction in MS. Neurology 2000, 54:558-564.

30. Mowry EM, Beheshtian A, Waubant E, Goodin DS, Cree BA, Qualley P, Lincoln R, George MF, Gomez R, Hauser SL, Okuda DT, Pelletier D: Quality of life in multiple sclerosis is associated with lesion burden and brain volume measures. Neurology 2009, 72:1760-1765.

31. Calabrese M, Filippi M, Gallo P: Cortical lesions in multiple sclerosis. Nat Rev Neurol 2010, 6:438-444.

32. Calabrese M, Rinaldi F, Grossi P, Gallo P: Cortical pathology and cognitive impairment in multiple sclerosis. Expert Rev Neurother 2011, 11:425-432.

\section{Pre-publication history}

The pre-publication history for this paper can be accessed here: http://www.biomedcentral.com/1471-2377/11/125/prepub

doi:10.1186/1471-2377-11-125

Cite this article as: Bastianello et al.: Changes in magnetic resonance imaging disease measures over 3 years in mildly disabled patients with relapsing-remitting multiple sclerosis receiving interferon $\beta$-1a in the COGnitive Impairment in MUltiple Sclerosis (COGIMUS) study. BMC Neurology 2011 11:125.

\section{Submit your next manuscript to BioMed Central and take full advantage of:}

- Convenient online submission

- Thorough peer review

- No space constraints or color figure charges

- Immediate publication on acceptance

- Inclusion in PubMed, CAS, Scopus and Google Scholar

- Research which is freely available for redistribution

Submit your manuscript at www.biomedcentral.com/submit
Ciomed Central 